Allen, Kevin, and Andrew Stevenson, An Introduction to the Italian Economy. (Glasgow Social \& Economic Research Studies, I.) London 1974. Martin Robertson. XII, $300 \mathrm{~S}$.

Tangermann, Stefan, Gemeinsame Agrarpreispolitik und nationale Wirtschaftspolitik in der EWG. Theoretische Anylyse der Funktionsbedingungen gemeinsamer Marktordnungen bei Wechselkursänderungen und empirische Untersuchung der Entwicklung in der Bundesrepublik Deutschland und Frankreich. (Schriften zur angewandten Wirtschaftsforschung, 33.) Tübingen 1974. J. C. B. Mohr (Paul Siebeck). XI, $276 \mathrm{~S}$.

Willgerodt, Hans, Der "Gemeinsame Agrarmarkt der EWG". Kritische Betrachtungen zu einer wirtschaftspolitischen Fehlkonstruktion. (Walter Eucken Institut, Vorträge und Aufsätze, 49.) Tübingen 1974. J. C. B. Mohr (Paul Siebeck). 75 S.

\title{
IV. Bevölkerung und Arbeit
}

\section{Bevolkerung und Wanderung}

Knodel, John E., The Decline of Fertility in Germany, 1871-1939. Princeton, New Jersey, 1974. Princeton University Press. XIX, 306 S.

\section{Arbeitsmarkt}

Enke, Harald, Ein aggregiertes okonometrisches Modell fïr den Arbeitsmarkt der Bundesrepublik Deutschland (auf der Basis von Vierteljahreswerten). Mit 35 Tab. und $20 \mathrm{Abb}$. im Text und 22 Tafeln. (Institut für angewandte Wirtschaftsforschung, Schriftenreihe: Bd. 25.) Tübingen I974. J. C. B. Mohr (Paul Siebeck). XXI, 273 S.

\section{Sozialpolitik}

Rothammer, Peter, Integration ausländischer Arbeitnehmer und ihrer Familien im Städtevergleich. Probleme, Maßnahmen, Steuerungsinstrumente. Unter Mitarb. von Susanne Heidtmann-Frohme, Carl-Henning von Ladiges, Norbert Semmer. (difu-Gutachten.) Berlin 1974. Deutsches Institut für Urbanistik. 370 S.

\section{Wirtschaftsordnung und soziale Verfassung}

\section{Wirtschaftssysteme}

Clapham, Ronald, Marktwirtschaft in Entwicklungsländern. Zur Anwendung und Leistungsfähigkeit des marktwirtschaftlichen Konzeptes. (Beiträge zur Wirtschaftspolitik, Bd. 21.) Freiburg im Breisgau I973. Rombach. 240 S.

In der Entwicklungspolitik hat lange Zeit die Diskussion um die "beste" Wirtschaftsordnung einen breiten Raum eingenommen. Das kann nicht überraschen. Einmal wurden die Investitionen privater Unternehmer als am 